\title{
PNEUMONIA AND MORTALITY RISK: STUDY ON DIABETIC AND NON-DIABETIC PATIENTS
}

\author{
NARMADHA MP ${ }^{1 *}$, NIKHNA JAYAN ${ }^{1}$, RON JOHNY $^{2}$
}

${ }^{1}$ Department of Pharmacy Practice, Nehru College of Pharmacy, Thrissur, Kerala, India. ${ }^{2}$ Department of Pulmonary, Medicine, Valluvanad Hospital Complex Ltd., Kerala, India. Email: narmadhasam@yahoo.co.in

Received: 25 May 2020, Revised and Accepted: 11 June 2020

ABSTRACT

Objective: Pneumonia, a frequent coexistent of diabetes, is an important cause of morbidity and mortality in diabetes. The diabetic population is not only prone to pulmonary infection but it is also prone to different comorbidity and complication. Therefore, the aim of the study was to assess and compare mortality in diabetic pneumonia and non-diabetic pneumonia group.

Methods: This was a prospective case-control study conducted in two hospitals which included 76 patients with Group 1 (patients with diabetics) and 70 patients with Group 2 (patients who are non-diabetics).

Results: Among 146 patients, mortality in diabetics was 5.47\% in comparison with non-diabetics $4.10 \%$. Patients in the diabetic group were significantly ( $\mathrm{p}=0.044)$ more among pneumonia severity index (PSI) Class IV-V (9.21\%) than PSI Class I-III (1.31\%). Most of the patients had predisposing condition or underlying disease, hypertension (87.50\% vs. 50\%), pulmonary (37.50\% vs. 83.33\%), neurological (37.50\% vs. $83.33 \%$ ), and renal disease (37.5\% in diabetic). The common complication in both groups was pleural effusion (50\%) and septic shock (25\%). Gram-negative bacteria (62.5\% vs. 33.33\%) and drug-resistant pathogens score (87.5\% vs. 66.66\%) were more prevalent in both groups.

Conclusion: Our study reveals that poor long-term glycemic control among patients with diabetes clearly increases the risk of hospitalization and mortality. In non-diabetic pneumonia patients, antibiotic-resistant bacteria and preexisting pulmonary disease act as a predictor for mortality.

Keywords: Diabetes mellitus, Pneumonia, Pneumonia severity index score, Morbidity, Mortality.

(C) 2020 The Authors. Published by Innovare Academic Sciences Pvt Ltd. This is an open access article under the CC BY license (http://creativecommons. org/licenses/by/4. 0/) DOI: http://dx.doi.org/10.22159/ajpcr.2020.v13i8.37267

\section{INTRODUCTION}

Pneumonia, "the captain of men of death," as described by William Osler, is one of the most common infectious diseases encountered in the clinical practice [1]. According to the WHO data, each year 3-4 million people, especially children and the elderly, die from pneumonia worldwide [2]. Pneumonia is a lung infection involving the lung alveoli (air sacs) and can be caused by microbes, including bacteria, viruses, or fungi, characterized primarily by inflammation of the alveoli in the lungs (alveoli are microscopic sacs in the lungs that absorb oxygen). The lungs are particularly susceptible to infection because they interact with the outside environment. They are exposed to about $10,000 \mathrm{~L}$ of air per day, which may contain infectious or toxic agents. Although pneumonia can occur in anyone, it occurs with increased frequency in individuals whose immune systems are deficient. Human immunodeficiency virus (HIV) infection, malnutrition, diabetes, renal failure, cancers, and treatment with immunosuppressive drugs are all risk factors for developing pneumonia. Infants and very young children are highly vulnerable, as are the elderly.

Diabetic patients are predisposed to colonization and pneumonia because of disease associated impairment in host defensive functions. At both extremes of age, this increased risk relates in part to impaired immunity. Patients who smoke or have underlying lung diseases, including chronic obstructive pulmonary disease (COPD), cystic fibrosis, congestive heart failure, and lung cancer, are also vulnerable, due to abnormalities in lung structure and function. Finally, patients with respiratory failure who are on mechanical ventilators are more prone to pneumonia [3]

There is a relative scarcity of studies examining diabetes mellitus (DM) as a potential risk factor for pneumonia. It is important to clarify whether diabetes and poor long-term glycemic control are a risk factor for pneumonia. It is hoped that the knowledge of relevant prognostic factors, identification of patients with drug-resistant pathogens (DRIPs) at initial diagnosis might be useful for early identification of patients at high risk requiring intensive care treatment. The aim of this study was to define the association with mortality in diabetic pneumonia and nondiabetic pneumonia group.

\section{METHODS}

This was a prospective case-control study conducted in two hospitals. A total of 146 pneumonia patients were included in the study in which 76 patients were Group 1 (pneumonia patients with diabetics) and 70 patients in Group 2 (pneumonia patients who are non-diabetics). The study was approved by the Institutional Ethics Committee (IEC/ NOV/18/10) and informed consent was obtained from each patient after explaining protocol of the study. Patients visiting hospital with pneumonia were screened from January 2019. Patients were enrolled to the study up to May 2019.

All diabetic patients and non-diabetic patients with confirmed pneumonia on clinical and radiological examination (X-ray) were included

HIV patients with aspiration pneumonia, HIV patients with pneumocystis pneumonia, and patients with pulmonary tuberculosis were excluded from the study.

A consecutive diabetic subjects and non-diabetic subjects with confirmed pneumonia were included in the study after informed consent. Pneumonia was diagnosed by symptoms and X-ray chest. The diagnosis of diabetes was based on the American Diabetes Association criteria. Detailed clinical history, general examination, and relevant investigation were carried out for all patients and noted in a predesigned pro forma. Pneumonia severity index (PSI) [4] was used to determine the severity and mortality. We obtained data on covariates potentially associated with pneumonia risk or prognosis: History of 
medication that being taken by patients based on conditions (use of glucocorticoids and other immunosuppressants within the year before the pneumonia-related admission and use of systemic antibiotics within 90 days before the admission, proton-pump inhibitors use, and other drugs use). Data on other major chronic diseases diagnosed during follow-up were collected from the registers of patients using hospital discharge or hospital outpatient visit diagnoses. A prediction rule for the using DRIPs occurrence was constructed using a simple counting of the number of risk factors (prior hospitalization, immunosuppression, previous use of antibiotics, use of gastric acid-suppressive agents, tube feeding, and non-ambulatory status) irrespective of pneumonia category to determine appropriate initial antibiotic treatment for patients with pneumonia [5].

All the data were entered into Microsoft Excel sheet and Statistical Package for the Social Sciences (SPS Software) version 22.0 software package was used for statistical analysis. Appropriate tests were applied according to type and distribution of data. Descriptive data were described using frequency, percentage, and measure of central tendency. Qualitative data were analyzed using Chi-square test. $\mathrm{p}<0.05$ was considered statistically significant.

\section{RESULTS}

This prospective case-control study consists of a total of 146 pneumonia patients, in which 76 patients were diabetic and 70 were non-diabetic group.

Among 146 patients, 10 (6.84\%) diagnosed as having hospital-acquired

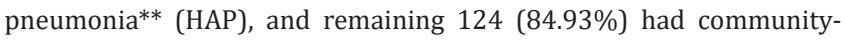
acquired pneumonia* (CAP). Within the diabetic patients, $63(82.89 \%)$ diagnosed as CAP and 6 (7.89\%) diagnosed as HAP. Aspiration pneumonia in the both groups was 7 (9.21\%) versus 5 (7.14\%). Health care-associated pneumonia** (HCAP) is a subdivision of HAP.

\section{*Notes}

- $\quad{ }^{*}$ CAP: Defined as pneumonia that is acquired outside the hospital

- $\quad * *$ HAP: Pneumonia that occurs $48 \mathrm{~h}$ or more after admission and did not appear to be incubating at the time of admission.

The new designation for pneumonia acquired in these environments is HCAP; patient populations include individuals residing in non-hospital health-care facilities (e.g., long-term nursing facilities, assisted living environments, and rehabilitation centers), patients undergoing outpatient procedures or therapies (hemodialysis, wound care, and infusion therapy), patients who have been recently discharged from the hospital setting, and those with significant underlying immunosuppression [5].

Of the 146 patients, 14 died ( 8 diabetics and 6 non-diabetics) in hospital. Among that, $8(10.52 \%)$ patients died in diabetics group and 6 patients $(8.57 \%)$ died in nondiabetics group. The mortality thus was $9.59 \%$. $p=0.583$ was not statistically significant.

Mortality of patients in diabetic group was significantly $(\mathrm{p}=0.044)$ more among PSI Class IV-V (9.21\%) than PSI Class I-III (1.31\%). Mortality of patients in nondiabetic group was not statistically significant.

\begin{tabular}{ll}
\hline $0-50$ points & Class I $0.1 \%$ mortality \\
$51-70$ points & Class II $0.6 \%$ mortality \\
$71-90$ points & Class III $0.9 \%$ mortality \\
$91-130$ points & Class IV $9.3 \%$ mortality [6] \\
$131-395$ points & Class V $27.0 \%$ mortality \\
\hline
\end{tabular}

- A patient with a DRIP score $<4$ can effectively be treated without broad-spectrum antibiotic coverage.

- A patient with a DRIP score of $\geq 4$ is more likely to require broadspectrum antibiotic coverage [7].

Drug resistance in diabetic group was more for $7(9.21 \%)$ patients (who died) compared to non-diabetic Group 4 (5.71\%) patients died with DRIP score $\geq 4$. In both groups, $\mathrm{p}$ value was statistically significant (0.000 vs. 0.0007$)$.

Among 146 patients, $73.97 \%$ of patients were in the age group between 55 and 89 years and the mean \pm SD age is $68 \pm 0.35$. Mortality was higher in age group greater than 65 years $(6.16 \%)$ and mortality rate was equal for both male and female with $4.79 \%$.

Among 10 HAP patients, $4(40 \%)$ died. Of the 124 CAP patients, 7 (5.64\%) died. Among 12 aspiration pneumonia cases, 3(25\%) died. Prior antibiotic use and hospitalization were more common risk factor in both groups. Most of the patients had predisposing condition (hypertension, pulmonary, neurological, and renal disease). Four were ex-smokers. The common complications in both groups were septic shock (25\% vs. $33.33 \%$ ). Pleural effusion (50\%) is more common in diabetes group. Diabetes combined with a glycated hemoglobin (HbA1c) level $\geq 6.5 \%$ was more in diabetic group. This may increase risk of pneumonia-related hospitalization and mortality. The number of patients infected with Gram-negative bacteria (GNB) and DRIP score was high in diabetic group.

\section{DISCUSSION}

The present population-based study included a broad group of patients with all types of pneumonia, making it possible to determine disease characteristics more exactly in the subgroup of patients with diabetes as an underlying pathology. Our study included 146 pneumonia patients, out of which $76(52.05 \%)$ were diabetic and $70(47.94 \%)$ were nondiabetics. Higher incidence of diabetic in pneumonia is because of alterations in immune and inflammatory mechanism. As prevalence of diabetes and pneumonia-related hospitalizations increase in the aging populations, accurate data are required to understand the clinical course and to potentially prevent pneumonia-related deaths in diabetics.

In the present study, during treatment for pneumonia, a total of 12 patients died in which $8(10.52 \%$ in 76$)$ in diabetic groups and 6 ( $8.57 \%$ in 70 ) in non-diabetic group. Out of 10 HAP patients, $4(40 \%)$ died which clearly shows that HAP has poor prognosis. In HAP, the majority of cases are caused by various rod-shaped Gram-negative organisms (Klebsiella pneumoniae (57.89\%), Pseudomonas aeruginosa (26.31\%), and Escherichia coli (7.89\%). Similar observations are made by Falguera et al. reported that mortality was more common in diabetic patients which was statistically significant [9]. Akbar also reported a significant difference in mortality between both the diabetic and nondiabetic groups [10]. In another study by Kornum et al. [11], mortality among diabetic patients was greater than that among other patients: (19.9\% vs. $15.1 \%$ ) After 30 days and (27\% vs. 21.6\%) after 90 days. A recent Spanish study by Falguera et al. [9] with CAP found that diabetes was associated with markedly increased 30-day mortality (adjusted RR 2.14). Mortality due to pneumonia in various hospital-based studies has been variable. In the British Thoracic Society, multicentric study recorded a low mortality of $5.7 \%$ which is on par with our study (9.59\%), higher mortality (ranging from $21 \%$ to $25 \%$ ) has been reported in other studies [12]. However, in another Indian study, a significantly higher mortality was noticed in patients aged 50 years or above and in those with underlying comorbid conditions [3].

The present study reported that mortality of patients in diabetic group was significantly $(p=0.044)$ more among PSI Class IV-V $(9.21 \%)$ than PSI Class I-III (1.31\%). Mortality of patients in non-diabetic group was more among PSI Class IV-V. Falguera et al. reported that majority of survivors in non-diabetics presented with PSI Class I-III in comparison with diabetics who in majority presented with Class IV-V which was statistically significant $(\mathrm{p}<0.01)$ [9]. In the patients who died, drug resistance in diabetic group was more for $9.21 \%$ of patients compared to $5.71 \%$ non-diabetic patients. In both groups, p value was statistically significant $(0.000$ vs. 0.0007$)$. This shows that drug resistance is an important factor for mortality in both groups. In diabetic group, frequent visit to hospital, prior antibiotic therapy, other comorbidities, medicine intake for these comorbidities, low immunity results in frequent infection history and drug resistance. 
Risk factors of mortality

When we analyzed the cause of death in pneumonia patients, it is realized that out of 8 deaths in diabetics, 7 (87.5\%) had hypertension, and $3(37.5 \%)$ patients had renal disease, neurological diseases, and respiratory problems (BA/COPD). In non-diabetics, out of 6 patients, $5(83.33 \%)$ had COPD. Shyama and Prudence reported that the most predominant comorbidity associated with respiratory tract infections was hypertension [13].

Hence, our study results point out that pneumonia with preexisting respiratory diseases along with hypertension can be a factor for poor prognosis and death.

\section{Mortality in diabetic group}

Diabetes combined with an HbA1c level $\geq 6.5 \%$ shows significant association $(p=0.0353)$ in our study with an increased risk of pneumonia-related hospitalization as well as mortality. The exact underlying pathophysiological mechanisms responsible for mortality

Table 1: Type of pneumonia in the study population

\begin{tabular}{lllll}
\hline & $\begin{array}{l}\text { Diabetic } \\
\mathbf{n = 7 6}(\mathbf{\%})\end{array}$ & $\begin{array}{l}\text { Non-diabetic } \\
\mathbf{n = 7 0}(\mathbf{\%})\end{array}$ & $\begin{array}{l}\text { Total } \\
\mathbf{n = 1 4 6}(\%)\end{array}$ & p-value \\
\hline HAP & $6(7.89)$ & $4(5.71)$ & $10(6.84)$ & 0.602 \\
CAP & $63(82.89)$ & $61(78.57)$ & $124(84.93)$ & 0.473 \\
Aspiration & $7(9.21)$ & $5(7.14)$ & $12(8.21)$ & 0.649 \\
pneumonia & & & & \\
\hline
\end{tabular}

Table 2: Clinical outcome of pneumonia of the study population

\begin{tabular}{lll}
\hline & $\begin{array}{l}\text { Diabetics } \\
\mathbf{n = 7 6 ( \% )}\end{array}$ & $\begin{array}{l}\text { Non-diabetics } \\
\mathbf{n = 7 0}(\%)\end{array}$ \\
\hline Survived & $68(89.47)$ & $64(91.42)$ \\
Died & $8(10.52)$ & $6(8.57)$ \\
Relapse/recurrent pneumonia & $2(2.63)$ & $1(1.42)$ \\
Shifted to other hospital & $3(3.93)$ & $3(4.28)$ \\
\hline
\end{tabular}

Table 3: Mortality in the study population

\begin{tabular}{lll}
\hline & Mortality & p-value \\
\hline Diabetics, $\mathrm{n}=76(\%)$ & $8(10.52)$ & 0.583 \\
Non-diabetics, $\mathrm{n}=70(\%)$ & $6(8.57)$ & \\
\hline
\end{tabular}

Table 4: Pneumonia mortality assessment using PSI scoring

\begin{tabular}{|c|c|c|c|c|c|c|}
\hline \multirow[t]{2}{*}{$\begin{array}{l}\text { PSI } \\
\text { class }\end{array}$} & \multicolumn{2}{|c|}{ Diabetic $n=76(\%)$} & \multirow{2}{*}{$\begin{array}{l}\text { p-value } \\
0.044^{*}\end{array}$} & \multicolumn{2}{|c|}{$\begin{array}{l}\text { Non-diabetic } \\
\mathrm{n}=70(\%)\end{array}$} & \multirow[t]{2}{*}{ p-value } \\
\hline & Died & Survived & & Died & Survived & \\
\hline I-III & $1(1.31)$ & $34(44.73)$ & & - & $\begin{array}{l}53 \\
(75.71)\end{array}$ & \\
\hline IV-V & 7 (9.21) & $34(44.73)$ & & 6 (8.57) & $\begin{array}{l}11 \\
(15.71)\end{array}$ & \\
\hline
\end{tabular}

PSI: Pneumonia severity index

Table 5: Pneumonia mortality assessment using drug resistance in pneumonia (DRIP) scoring

\begin{tabular}{|c|c|c|c|c|c|c|}
\hline \multirow[t]{2}{*}{$\begin{array}{l}\text { Drip } \\
\text { scoring }\end{array}$} & \multicolumn{2}{|c|}{ Diabetic $n=76(\%)$} & \multirow{2}{*}{$\begin{array}{l}\text { p- } \\
\text { value } \\
0.000 *\end{array}$} & \multicolumn{2}{|c|}{$\begin{array}{l}\text { Non-diabetic } \\
n=70(\%)\end{array}$} & \multirow{2}{*}{$\begin{array}{l}\text { p- } \\
\text { value } \\
0.000^{*}\end{array}$} \\
\hline & Died & Survived & & Died & Survived & \\
\hline$<4$ & $1(1.31)$ & $57(75)$ & & $2(2.85)$ & $56(80)$ & \\
\hline$\geq 4$ & $7(9.21)$ & $11(14.47)$ & & $4(5.71)$ & $8(11.42)$ & \\
\hline
\end{tabular}

in patients with DM admitted to hospital for pneumonia are not well known, but the following explanations could be proposed: Pneumonia may be a trigger which accelerates preexisting chronic diseases, through the activation of a persisting pro-inflammatory status and the precipitation of fatal cardiovascular events; and pneumonia itself and/ or antibiotic therapies could determine a worsening of renal function increasing the risk of morbidity and mortality. The previous populationbased studies by Benfield et al. [14] and Valdez et al. [15] showed higher incidence of death due to infections in subjects with diabetes could not assess whether these differences were due to increased susceptibility to infections or worse outcomes after infection. Underlying biological mechanisms increased mortality among diabetic patients hospitalized

Table 6: Age and gender of the study population

\begin{tabular}{llll}
\hline & Survived $\mathbf{n = 1 4 6}(\mathbf{\%})$ & Death $\mathbf{n = 1 4 6}(\mathbf{0})$ & p-value \\
\hline $\begin{array}{l}\text { Gender } \\
\text { Male }\end{array}$ & $73(50)$ & $7(4.79)$ & \\
$\quad$ Female & $59(40.41)$ & $7(4.79)$ & 0.704 \\
Age & & & \\
$\quad<65$ & $66(45.20)$ & $5(3.42)$ & 0.309 \\
$>65$ & $66(45.20)$ & $9(6.16)$ & \\
\hline
\end{tabular}

Table 7: Assessment of risk factors causing mortality in pneumonia patients

\begin{tabular}{|c|c|c|c|}
\hline & $\begin{array}{l}\text { Mortality } \\
\text { in diabetics } \\
n=8(\%)\end{array}$ & $\begin{array}{l}\text { Mortality in } \\
\text { non-diabetics } \\
n=6(\%)\end{array}$ & p-value \\
\hline HAP & $2(25)$ & $2(33.33)$ & 0.732 \\
\hline CAP & $4(50)$ & $3(50)$ & 0.584 \\
\hline Aspiration pneumonia & $2(25)$ & $1(16.66)$ & 0.706 \\
\hline \multicolumn{4}{|l|}{ Other risk factors } \\
\hline Prior antibiotic use & $5(62.5)$ & $3(50)$ & 0.639 \\
\hline Hospitalization & $4(50)$ & $3(50)$ & 1 \\
\hline Dialysis & $2(25)$ & $1(16.67)$ & 0.706 \\
\hline Ventilator use & $1(12.5)$ & $1(16.67)$ & 0.825 \\
\hline Gastric acid suppressor use & $1(12.5)$ & $2(33.33)$ & 0.347 \\
\hline \multicolumn{4}{|c|}{ Comorbidity } \\
\hline HTN & $7(87.50)$ & $3(50)$ & 0.124 \\
\hline Heart disease & & $3(50)$ & \\
\hline Respiratory disease & $3(37.50)$ & $5(83.33)$ & 0.086 \\
\hline Neurological disease & $3(37.50)$ & $2(33.33)$ & 0.532 \\
\hline Chemotherapy & & $2(33.33)$ & \\
\hline Renal disease & $3(37.50)$ & & \\
\hline Thyroid dysfunction & $2(25)$ & & \\
\hline \multicolumn{4}{|l|}{ Complication } \\
\hline Pleural effusion & $4(50)$ & & \\
\hline Sepsis & $2(25)$ & $2(33.33)$ & 0.732 \\
\hline Respiratory failure & $1(12.5)$ & $1(16.67)$ & 0.825 \\
\hline \multicolumn{4}{|l|}{ HBA1c in diabetics } \\
\hline$<6.5$ & $1(12.5)$ & $5(83.3)$ & \\
\hline$>6.5$ & $7(87.5)$ & $1(16.6)$ & $0.0353 *$ \\
\hline $6.5-7.5$ & $3(37.5)$ & & \\
\hline $7.6-8.5$ & $1(12.5)$ & $1(16.6)$ & \\
\hline $8.6-9.5$ & $2(25)$ & & \\
\hline \multicolumn{4}{|l|}{$9.6-10.5$} \\
\hline $10.6-11.5$ & $1(12.5)$ & & \\
\hline \multicolumn{4}{|l|}{$11.6-12.5$} \\
\hline \multicolumn{4}{|l|}{ Smokers } \\
\hline Ex-smoker & $3(37.5)$ & $1(16.6)$ & 0.393 \\
\hline \multicolumn{4}{|l|}{ Current smoker } \\
\hline \multicolumn{4}{|l|}{ Spectrum of organism } \\
\hline GNB & $5(62.5)$ & $2(33.33)$ & 0.280 \\
\hline \multicolumn{4}{|l|}{ GPC } \\
\hline DRIP score & & & \\
\hline Greater than/equal to 4 & $7(87.5)$ & $4(66.66)$ & 0.347 \\
\hline
\end{tabular}


for pneumonia may include decreased leukocyte function and harmful effects of hyperglycemia both these factors contribute to this study also. However, a high blood sugar value at presentation shows significant association with mortality. Hence, maybe mortality in diabetic patients was due to uncontrolled diabetes, associated comorbid condition and high risk of bacteraemia and septicemia. Over recent years, the length of stay appears to have decreased in diabetic group as a result of several strategies and practical guidelines that have been proposed to safely reduce the number of hospitalization days and mortality [16].

\section{Mortality in non-diabetic group}

Pneumonia with preexisting respiratory diseases can lead to poor prognosis and death. Next factor is drug resistance, an emerging predictor for mortality. Drug resistance is the reduction in effectiveness of a medication such as an antimicrobial in treating a disease or condition. Usually, beta-lactamase inhibitor +cephalosporin/penicillin and macrolides were given commonly in non-diabetic groups. The existence of the antibiotic-resistant bacteria (GNB - P. aeruginosa and K. pneumoniae) can easily lead longer hospital stays, high mortality and morbidity, and increased treatment costs [16]. These contribute to our study also. The spread of multidrug-resistant GNB in the hospital setting is now seen as a globalized threat (Centers for Disease Control and Prevention CDC, 2013), and ICU patients are especially exposed to the risk. The hospital infection control authorities would not be able to effectively stop bacterial circulation in the hospital without applying the basic rules of sanitation and efficient use of disinfectants. Unfortunately, the emergence of bacterial resistance following the introduction of new drugs appears as an unavoidable and endless process and every initiative aiming at limiting the selective pressure of antibiotics on the intestinal flora is more than ever justified (Centers for Disease Control and Prevention CDC, 2013).

\section{CONCLUSION}

Our analysis revealed that hyperglycemia is a strong predictor for mortality following pneumonia in diabetic group. Uncontrolled glucose level results in decreased immunity, comorbidity, complication, and resistance to drug therapy. Probable reasons for uncontrolled diabetes in the present study which had been conducted among lower middle class or poor population were lack of awareness toward pneumonia, diabetes, and instruction about diet and lifestyle. In non-diabetic pneumonia patients, antibiotic-resistant bacteria and preexisting pulmonary disease act as a predictor for mortality.

All pneumonia patients after their discharge from the hospital should fit in structured follow-up care. Structured follow-up care includes the followup of comorbid conditions and the initiation of recommended preventive measures such as antipneumococcal and anti-influenza vaccination, the avoidance of drugs that increase the risk, smoking cessation, and treatment of dysphagia, if present. Good glycemic control of diabetes, timely treatment with antibiotic according to sensitivity report, and also good diet and supportive treatment improve outcome of pneumonia in diabetic patients. However, patients with diabetes as well as patients with non-diabetes need additional care for better control and management even though diabetics are more prone to infections and drug resistance.

Health-care professionals' common opinion is diabetes in pneumonia which is more risky than non-diabetics pneumonia group. This is true as per earlier studies reported. However, our study shows narrow difference in mortality between the two groups. Therefore, pneumonia in both diabetics and non-diabetics has to be given equal attention and importance in health sectors.

\section{ACKNOWLEDGMENT}

The authors would like to thank all the patients for participating in the study.

\section{AUTHORS' CONTRIBUTIONS}

Dr. Narmadha MP made substantial contributions to interpretation, drafting the article, and critical revision. Collection of articles, studying the materials, interpretation, and preparation of this journal was done by Nikhna Jayan. Dr. Ron Johny contributed to data analysis and interpretation.

\section{CONFLICTS OF INTEREST}

The author declared that there are no conflicts of interest related to this study.

\section{AUTHORS' FUNDING}

There was no funding for this study. Minor expenses were done by the author themselves.

\section{LIMITATIONS OF THE STUDY}

This study suffers from few of the following limitations: We were not able to follow up the patients after discharge as well as to find out 30day mortality/90-day mortality.

\section{REFERENCES}

1. Berk SL. Bacterial pneumonia in the elderly: The observations of Sir William Osler in retrospect. J Am Geriatr Soc 1984;32:683-5.

2. Kumar TC, Rafiudeen R, Rashmi K. A study of clinical and etiological profile of community-acquired pneumonia with special reference to atypical pneumonia. Ann Nigerian Med 2017;11:6-11

3. Cilloniz C, Martin-Loeches I, Garcia-Vidal C, San Jose A, Torres A. Microbial etiology of pneumonia: Epidemiology, diagnosis and resistance patterns. Int J Mol Sci 2016;17:2120.

4. Pachon J, Prados MD, Capote F, Cuello JA, Garnacho J, Verano A. Severe Community acquired pneumonia. Etiology, prognosis and treatment. Am Rev Respir Dis 1990;142:369-73.

5. Fissell WH. Antimicrobial dosing in acute renal replacement. Adv Chronic Kidney Dis 2013;20:85-93.

6. Fine MJ, Smith MA, Carson CA, Mutha SS, Sankey SS, Weissfeld LA, et al. Prognosis and outcomes of patients with community-acquired pneumonia. A meta-analysis. JAMA 1995;274:134-40.

7. Webb BJ, Dascomb K, Stenehjem E, Vikram HR, Agrwal N, Sakata K, et al. Derivation and multicenter validation of the drug resistance in pneumonia clinical prediction score. Antimicrob Agents Chemother 2016;60:2652-63.

8. Bhambar S, Deore P, Rathod R, Janrao S. Pneumonia in diabetics: Clinico-bacteriological profile and outcome. Int J Med Health Res 2017;3:62-6

9. Falguera M, Pifarre R, Martin A, Sheikh A, Moreno A. Etiology and outcome of community acquired pneumonia in patients with diabetes mellitus. Chest 2005;128:3233-9.

10. Akbar DH. Bacterial pneumonia: Comparison between diabetics and non-diabetics. Acta Diabetol 2001;38:77-82.

11. Kornum JB, Thomsen RW, Riis A. Diabetes glycemic control and risk of hospitalization with pneumonia. Diabetes Care 2008;31:1541-5.

12. Pachon J, Prados MD, Capote F, Cuello JA, Garnacho J, Verano A. Severe Community acquired pneumonia. Etiology, prognosis and treatment. Am Rev Respir Dis 1990;142:369-73.

13. Shyama K, Prudence AR. Improving antibiotic prescribing pattern and assessment of Co-morbidities associated with respiratory tract infections. Int J Pharm Pharm Sci 2017;9:283-6.

14. Benfield T, Jensen JS, Nordestgaard BG. Influence of diabetes and hyperglycaemia on infectious disease hospitalisation and outcome. Diabetologia 2007;50:549-54.

15. Valdez R, Narayan KM, Geiss LS, Engelgau MM. Impact of diabetes mellitus on mortality associated with pneumonia and influenza among non-Hispanic black and white US adults. Am J Public Health 1999;89:1715-21.

16. Khan MA, Naqvi SB, Alam S, Ali SI, Rizvi M, Hussain M, et al. Survey base study on current trend of treatment of community-acquired pneumonia in Karachi. Int J Pharm Pharm Sci 2015;7:162-7. 